\title{
Editorial
}

\section{¿Qué significa para Latinoamérica la decadencia del poder mundial?}

La cruenta invasión israeli al Líbano fue un episodio más de la impunidad con la que, al amparo del poderio norteamericano, se cometen las más crasas violaciones a los derechos humanos y al derecho internacional. Sin embargo, hubo un aspecto en el que supuso una diferencia con respecto al pasado. Por primera vez, la condena contra las acciones israelies no venía solamente de los paises árabes, o de la izquierda. Algunos gobiernos occidentales condenaron en voz alta la invasión israelí, sin que las usuales descalificaciones surtieran efecto.

De igual forma, la guerra estadounidense en Irak ha traido un efecto similar. Un informe de los servicios de inteligencia norteamericanos, hecho público en la última semana de septiembre, indica algo que los opositores a la guerra en Irak ya habian señalado con mucha anticipación: La politica "antiterrorista" de la administración Bush ha exacerbado el sentimiento antiestadounidense, no sólo en Irak, sino en el mundo árabe, y constituye el sustento del que se nutren los movimientos fundamentalistas y las organizaciones a las que se vincula con actos terroristas. El fiasco de la politica de seguridad de G. W. Bush se critica también en voz alta. 
No obstante que estas criticas a la potencia hegemónica no traigan consigo un cambio en su politica exterior, lo cierto es que podrian interpretarse como un sintoma de la decadencia de su poder. El presente momento histórico se caracterizaría precisamente por la crisis terminal de la hegemonía estadounidense. Al menos es eso lo que plantea Immanuel Wallerstein, en el articulo intitulado "The curve of American power", aparecido en New Left Review en fecha reciente. Según el autor, las administraciones norteamericanas, de Nixon a Clinton, trataron de revertir el declive mediante alianzas estratégicas con Europa Occidental y Japón, con el fortalecimiento de su aparato militar y su influencia económica en el llamado Tercer Mundo. El esquema funcionaba desde la premisa de la confrontación bipolar con la antigua URSS. Colapsada esta última, el esquema se derrumbó. El mundo unipolar no implicó necesariamente la recuperación del poderio norteamericano. La ola critica hacia el neoliberalismo y la globalización en los paises pobres hicieron ver que la desaparición de la URSS no era "el fin de la historia".

Un hecho importante fueron los atentados terroristas del 11-S. Ello trajo consigo el fortalecimiento del ala neoconservadora de Washington y con él, un esquema de politica internacional destinado a revertir el declive del poder estadounidense mediante una politica militarista. Esto ha acentuado dicho declive, según el articulista, pues "el mundo ha entrado a una división del poder geopolítico relativamente desestructurada y multilateral, con un número de centros regionales, cuya magnitud de fuerza es variable, que están maniobrando por obtener ventajas" en el escenario internacional. Esto sería una sintesis apretada de lo que plantea Wallerstein.

La pregunta que surge por estas latitudes es la que encabeza este editorial. Dando por sentado el diagnóstico de Wallerstein, ¿qué significa esta decadencia para los paises pobres?

En primer lugar, cabe anotar que aunque ha fracasado la apuesta norteamericana en Medio Oriente, en la que se conseguiría el doble objetivo de recuperar el poder perdido y de mandar una advertencia a los gobiernos que se encuentran reacios a aceptar sus designios, este fracaso no se vislumbra, por ahora, como un cese a la matanza global. La condena moral, que ha tenido eco en todo el globo, hacia los hechos del Libano, Afganistán e Irak, demuestra que, si esa decadencia es un hecho, se está pagando muy alta en términos humanos. 
Esto lleva a otra consideración. El superpoder mundial se está derrumbando, pero no hay un referente claro que oponerle. Han surgido, como dice Wallerstein, diversos centros regionales —algunos de ellos, en el Tercer Mundo-que están buscando una posición ventajosa en medio del caos. En el caso particular de América Latina, esto implica la necesidad de crear esos nuevos referentes. Unos referentes en los que un modelo distinto de convivencia sobre relaciones más humanizadoras sea la base.

Se dice esto por varias razones. Una, América Latina no ha sido capaz de resolver su problema histórico: No ha sabido "apropiarse de sus propias posibilidades"; por el contrario, las claves para entenderse a si misma, para organizar su modo de vida, para establecer sus proyectos históricos, ha visto hacia fuera. Si surge un nuevo "superpoder" mundial —Japón, China, la Unión Europea-, ¿continuará América Latina confiándole las claves de su historia?

En segundo lugar, algunos de estos "centros regionales" de poder, queriendo frenar a los Estados Unidos, han partido de sus mismas premisas: el armamentismo. ¿Quedará otra opción ante la politica unilateralista de Washington?, se puede preguntar. El caso de Corea del Norte, incluida en el "Eje del Mal" de G. W. Bush sería una confirmación de esta tesis. Pyongyang no goza del beneplácito de la Casa Blanca, pero el que tenga armas nucleares en su haber parece haber sido suficiente para que no se haya enviado tropas norteamericanas para "combatir el terrorismo" y "establecer la democracia", por mucho que las credenciales democráticas del gobierno norcoreano estén en entredicho.

Pero proyectarse una "paz perpetua" basada en la posesión de armamento nuclear sería un sinsentido. Implicaría volver a la carrera armamentista propia de la Guerra Fría, en la cual las hostilidades entre las dos superpotencias no llegaron a romperse, pero si a desencadenar un desarrollo frenético de la tecnología bélica. Por otro lado, pensar, desde la perspectiva de los paises pobres, en tener ojivas nucleares para hacerse respetar por los Estados Unidos, mientras las mayorías viven en condiciones indignas, es inviable desde cualquier punto de vista.

Un paso importante en buscar un modelo de convivencia internacional son los distintos esfuerzos, por parte de muchos gobiernos latinoamericanos, 
de plantear una nueva agenda internacional a partir de las perspectivas propias. Ese proceso de redimensionamiento de las politicas internacionales pasa por dinámicas de integración regional, tanto de carácter económico como de carácter político y social, pero también por replantear las premisas de la politica mundial. Un ejemplo valioso de ello es el actual debate sobre el papel de las Naciones Unidas. Evidenciados los problemas del unilateralismo norteamericano y del exclusivo poder de veto de Washington a las decisiones del Consejo de Seguridad de las Naciones Unidas, están en el ambiente muchas propuestas, como la de reformular la composición del Consejo de Seguridad y volver vinculantes las resoluciones del organismo mundial. Se trataría, en definitiva, de sentar las bases para lo que el filósofo Alejandro Serrano Caldera ha denominado "un nuevo contrato social mundial".

Una buena parte de los paises sudamericanos se ha comprometido en este proceso de crear una nueva agenda regional, a partir de concepciones $y$ objetivos comunes, que partan de las realidades propias. Centroamérica ha quedado rezagada de este proceso, que tiene mucho que ver con la llegada de partidos democráticos y de movimientos sociales de izquierda al poder. En el istmo centroamericano son evidentes las contradicciones de la globalización impulsada por Washington, pero también es evidente la ausencia de referentes alternativos válidos. Muchas veces, aquello que pasa como "alternativo" frente al poder de las élites empresariales, no es más que la resurrección de viejos liderazgos de signo caudillista en la izquierda, o la amenaza de un nuevo populismo de derechas. Estas "alternativas" no son tales y poco o nada pueden hacer frente a la dominación de la superpotencia hegemónica. Centroamérica amenaza con seguir quedándose en los márgenes de la periferia, en vez de asumir un papel activo en la reconfiguración del orden mundial.

Como se ve, el declive del poder estadounidense deja, en los paises latinoamericanos, más desafios que certezas. Estos desafios se podrán enfrentar mejor en la medida en que se abandonen las visiones cortoplacistas en la gestión de la cosa pública y en las relaciones internacionales, y en la medida en que, en vez de entregar su destino a "redentores" ocasionales o a administradores de la corrupción y la crisis, las sociedades latinoamericanas, pero en especial, las centroamericanas, "hagan oír su voz", como exhortaba Ignacio Ellacuría. Pero para esto, hace falta primero pensar por cuenta propia.

\section{6}

